REVISTA DE DERECHO UNED, NÚM. 14, 2014

Premio de artículos jurídicos «GARCÍA GOYENA» (Curso 2013-2014)

Premio: segundo premio

\title{
EL CONTRATO DE GESTIÓN HOTELERA
}

\author{
THE HOTEL «MANAGEMENT AGREEMENT»
}

Anselmo Martínez CañEllas

Profesor Titular de Derecho mercantil de la Universidad de las Islas Baleares

Resumen: El presente trabajo analiza el régimen más utilizado por las cadenas hoteleras para su expansión nacional e internacional: el contrato de gestión hotelera. Es un contrato en el que el propietario del hotel encarga la gestión del mismo a una empresa hotelera, que recibirá una compensación por su gestión y entregará los beneficios de la misma al propietario del hotel. Su régimen jurídico se asemeja al del contrato de arrendamiento de servicios cuando el interés del gestor se limita a la mera gestión. No obstante, lo más frecuente es que el gestor, además de la gestión, esté interesado en integrar el hotel en su cadena hotelera, y haga uso de un know how estandarizado y utilice una marca propia, en cuyo caso, su naturaleza es más próxima al contrato de mandato mercantil, es decir, el contrato de comisión, o mejor, al contrato de agencia, al ser un mandato duradero en el tiempo. En este caso, la legislación sobre el contrato de agencia es aplicable, aunque nunca imperativamente, pues el gestor hotelero que actúa como agente tiene una posición de fuerza que no merece mayor protección legal que el propietario del hotel.

Palabras clave: contrato de gestión hotelera, cadena hotelera, know how, contrato de agencia. 
Abstract: The present work analyses the regime of the hotel management agreement (HMA), the contract used more fequently by hotel chains in order to achieve an international and national expansion. In the HMA, the hotel owner puts the manager in charge of the hotel, paying him a management fee, and the manager gives the hotel owner the benefits. Its legal regime is similar to the contract of services when the interest of the manager is solely the management. Nevertheless, in the most common HMA, the manager is interested in integrating the hotel in its hotel chain, and in using an standarized know how and its own trademark. In this case, the legal nature of the contract is similar to the agency contract, so the Agency contract Act is applicable, but never as a compulsory norm, because the hotel manager is preponderant in the HMA, and does not deserve more legal protection than the hotel owner.

Key words: hotel management agreement, HMA, hotel chain, know how, agency.

\section{INTRODUCCIÓN}

El presente artículo pretende aclarar el régimen del contrato de mayor crecimiento utilizado actualmente por las cadenas hoteleras para su expansión, tanto nacional ${ }^{1}$, como internacional ${ }^{2}$. Se trata de un contrato atípico que ha sido escasamente analizado por la doctrina y la jurisprudencia españolas.

\section{ESTRUCTURACIÓN DE UNA CADENA HOTELERA}

La colaboración inter-empresarial hotelera puede basarse en capital o en relaciones contractuales. La contractual es más propia de sectores donde elementos de capital intensivo como el inmobiliario pueden ser separados de los de know how, como los servicios, lo que se da en el sector hotelero ${ }^{3}$. Bajo una misma marca, la cadena hotelera integra negocios de alojamiento turístico en propiedad, en arrenda-

${ }^{1}$ En 2012, el 30\% de las plazas hoteleras en España se gestionaban mediante gestión o management hotelero.

${ }^{2}$ Es el modelo seguido tradicionalmente las multinacionales estadounidenses (Marriot, Hilton, Sheraton, Four Seasons, etc), y, actualmente por las españolas (Meliá, Barceló, Riu, NH).

${ }^{3}$ Contractor, Farok J./ Kundu, Sumit K. «Modal Choice in a World of Alliances: Analyzing Organizational Forms in the International Hotel Sector». Journal of International Business Studies, Vol. 29, No. 2 (2nd Qtr, 1998), p. 326. 
miento de local, en arrendamiento de negocio, en régimen de franquicia y en régimen de gestión. La opción entre una u otra modalidad depende de diversos factores:

- La propiedad suele preferirse cuando hay fondos suficientes, pues supone una alta inversión ${ }^{4}$, y mantiene secreto el know how.

- El arrendamiento de local o de negocio se asume cuando los fondos son insuficientes y la cadena quiere asumir la gestión y el riesgo ${ }^{5}$.

- La franquicia la escoge la cadena cuando no quiere asumir ni la gestión (aunque sí controlarla), ni el riesgo (pues se cobra por ingresos, indexados con la inflación, y que se cobran antes que la determinación de beneficios, pues para estos debe esperarse hasta después del cierre del ejercicio).

- La gestión de negocios de alojamiento turístico es escogida por la cadena que no quiere asumir el riesgo pero sí la gestión, pues el control de la gestión propio de la franquicia puede ser tan complejo y costoso como gestionarla directamente, y porque gestionando directamente, la cadena se evita el riesgo de que el propietario no asimile su modelo de negocio.

Otros factores a tener en cuenta son el interés de la compañía en crecer rápidamente horizontalmente (control del mercado de alojamiento) o verticalmente (garantizar la plena ocupación de sus redes de agencias de viaje y transporte).

Cuando la cadena hotelera quiere crecer en el extranjero tiene también en consideración las condiciones de seguridad jurídica, económica, política o cultural. A mayor inseguridad, se prefieren los contratos de gestión de negocios de alojamiento turístico o de franquicia $^{6}$. Y en caso de que la inseguridad jurídica afecte a los derechos de propiedad industrial e intelectual, la preferencia es por el contrato de gestión. Ello es lógico, pues en el contrato de gestión la cadena es quien cobra los ingresos de los que detrae la cantidad correspondiente a su retribución. Sin embargo, la cadena prefiere contratos de arrendamiento o la explotación en propiedad en países con seguridad,

${ }^{4}$ Alcover Garau, Guillermo. "Aproximación al contrato de gestión hotelera», en Revista de Derecho mercantil. N. ${ }^{\circ}$ 237, 2000, p. 1003.

${ }^{5}$ Alcover Garau, Guillermo. "Aproximación al contrato de gestión hotelera», en Revista de Derecho mercantil. N. ${ }^{\circ} 237,2000$, p. 1004.

${ }^{6}$ Contractor, Farok J./ Kundu, Sumit K. «Modal Choice in a World of Alliances: Analyzing Organizational Forms in the International Hotel Sector». Journal of International Business Studies, Vol. 29, No. 2 (2nd Qtr., 1998), p. 336. 
salarios bajos y donde el mercado no esté maduro, pues permiten un nivel más alto de retribución, al cobrar sobre beneficios.

\subsection{Concepto de contrato de gestión de negocios de alojamiento turístico}

El contrato de gestión de negocios de alojamiento turístico, o de gestión hotelera, en derecho anglosajón Hotel Management Agreement (HMA), puede definirse jurídicamente como aquel en el que la cadena hotelera gestiona en nombre y por cuenta del titular del hotel la explotación del mismo a cambio de una contraprestación ${ }^{7}$.

Desde un punto de vista económico, un contrato de gestión hotelera es un contrato a largo plazo, de al menos diez años, en el que los propietarios legales del hotel (negocio) llegan a un acuerdo con la cadena hotelera para que gestione el hotel de manera diaria, normalmente bajo la marca reconocida de esta última. El control de calidad, gestión diaria y contratación de los cuadros directivos recae principalmente en la cadena hotelera, pero la gestión se realiza como si la propiedad fuera parte de la cadena hotelera. Los clientes del hotel no deben percibir la diferencia. La cadena percibe la remuneración por su gestión, consistente en un porcentaje de los ingresos brutos (con unos mínimos y cantidades fijas pagadas como provisión). Además la cadena hotelera puede obtener márgenes extra sobre los suministros y material que vende a la propiedad. También es posible que se añadan bonus a la remuneración, como porcentaje sobre los beneficios. Además, la cadena puede percibir ingresos extras por las tarifas derivadas del uso de la central de reservas de la cadena hotelera ${ }^{8}$.

\subsection{Antecedentes}

Los antecedentes de este contrato los encontramos en el derecho anglosajón del siglo XIX ${ }^{9}$, donde se explotaban empresas en las colonias por medio de managing agencies con directivos británicos. Este modelo fue seguido en Francia, donde el mandante conseguía con

${ }^{7}$ Alcover Garau, Guillermo. «Aproximación al contrato de gestión hotelera», en Revista de Derecho mercantil. N. ${ }^{\circ} 237,2000$, p. 1003.

${ }^{8}$ CONTRACTOR, Farok J./ KUNDU, Sumit K. «Modal Choice in a World of Alliances: Analyzing Organizational Forms in the International Hotel Sector». Journal of International Business Studies, Vol. 29, No. 2 (2nd Qtr., 1998), p. 329.

${ }_{9}^{9}$ Pérez Moriones, Aránzazu. El contrato de gestión hotelera. Ed. Tirant lo Blanch. 1998, p. 67-78. 
este contrato eludir la responsabilidad, cargándola a la empresa gestora, pero aprovechaban sus beneficios ${ }^{10}$. También en el siglo XIX, Alemania utilizó este contrato para el desarrollo de la explotación de ferrocarriles en países extranjeros. La estructura contractual consistía en la creación de empresas mixtas, con forma de sociedad anónima, cuya dirección era encomendada a otra empresa de gestión ${ }^{11}$.

Es en el sector energético de los Estados Unidos, en los años veinte del siglo pasado, donde se desarrolla el contrato de gestión como hoy lo conocemos. Con él se concentró el sector eliminando la competencia y extendiéndose a los sectores de seguros, medios de comunicación, y el petrolero. Actualmente los usan empresas de capital riesgo (Private Equity), que suelen invertir en sectores diversos sobre los que no tienen experiencia, ni les interesa adquirirla, pues solo buscan un retorno rápido de su inversión, comprando empresas para revenderlas en un plazo corto o medio (de cinco a siete años) ${ }^{12}$.

\subsection{Derecho comparado}

En Derecho comparado, el contrato de gestión hotelera se califica como contrato de representación, como el contrato de comisión o el de agencia. En países donde el contrato de agencia no está regulado, como Cuba, los tribunales (en el caso de Cuba, la Corte de arbitraje de la Cámara de Comercio de La Habana), utilizan la normativa de los contratos de comisión y mandato para integrar el contrato. En derecho anglosajón, la jurisprudencia equipara el concepto de gerente hotelero al concepto de representante (agent). En Francia, se regula el contrato de gestión como contrato de mandato, con peculiaridades.

${ }^{10}$ Martí Miravalls, Jaume. "El contrato de gérance-mandat: aproximación a los contratos de gestión empresarial». Revista Aranzadi de Derecho Patrimonial, 2008-2, $\mathrm{n}^{\circ} 21$, p. 3 .

${ }^{11}$ La jurisprudencia primero, y la ley después, acabaron con la confusión entre órgano de administración y empresa de gestión, obligando a que fuera el órgano de administración de la sociedad anónima quien contratara con la empresa de gestión: el caso Rümanischen Eisenbahngesellschaft declara que la dirección de una Aktion Gesellschaft no puede cederse mediante contrato por ser contrario al 227 ADHGB (criterio seguido en la normativa societaria alemana actualmente en vigor). Esta cuestión es relevante en cuanto a la destitución de la empresa de gestión, pues no corresponde a la Junta de Socios, sino al órgano de administración. Por su parte, en el caso Deutsch-Amerikanische Petroleumgesellschaft mit Deutsche Petroleumverkaufgesellschaft $m b H$ Vertrag, se consideró que era nula, por leonina y contraria al parágrafo 138 BGB, la cláusula que permitía a la primera sociedad nombrar y destituir administradores de la segunda, y estos y la Junta adoptar acuerdos impuestos por la primera.

${ }^{12}$ Para estas empresas, contratar a una empresa de gestión hotelera les sale rentable, pues estos contratos suelen generar un $25 \%$ de beneficio al propietario. 
La Loi 2005-882, de 2 de agosto, regula el contrato de Gérance-mandat en pequeñas y medianas empresas. Si el gerente sea una persona física determinada, se aplica la legislación laboral ${ }^{13}$. Hasta entonces se le aplicaba el régimen del mandato de los arts. 1984 y siguientes del Code Civil. La Ley añade los arts. L 146-1 a 146-4 al Code Civil. El art. L 146-1. Define el contrato y establece obligaciones registrales. El contrato se caracteriza por la gestión de un fondo de comercio ajeno, en propiedad del mandate, que sufre los riesgos de la explotación, que fija una misión, un marco de poder de gestión, que puede ser amplio, pero no ilimitado (con libertad para gestionar su régimen laboral propio, la contratación y la subcontratación de funciones, que asume únicamente el gestor). La inscripción no es constitutiva, pero sí protectora de terceros ${ }^{14}$. El art. L 146-2 regula la información precontractual que se desarrolló por Decreto 259, de 3 de marzo de 2006, sobre forma, contenido -red, retribución, duración y causas de rescisión-y plazo de entrega del documento precontractual. El art. L 146-3 regula la retribución del gerente, indicando que es una obligación de me$\operatorname{dios}^{15}$, y señalando una comisión mínima del gerente que, a falta de pacto, la decide el Ministro de la pequeña y mediana empresa. Finalmente, el art. L 146-4 regula la extinción del contrato, que es de libre decisión por parte del gerente que, además, tiene derecho a una indemnización igual a las comisiones cobradas o a la comisión mínima de 6 meses anteriores o la percibida en la ejecución del contrato inferior a 6 meses. En realidad, esta normativa está pensando en los contratos de gestión en los que el gestor es parte débil del contrato, de ahí que incorpore un régimen protector de este. Por ello, en caso de que tomemos como modelo de Derecho comparado el ordenamiento francés debemos ser conscientes de las particularidades del contrato de gestión hotelera (por ejemplo, la marca hotelera es del gerente, no del mandante, y es el mandante quien tiene la posición débil).

\subsection{Características y naturaleza jurídica}

El contrato de gestión hotelera es un contrato consensual, sinalagmático y de naturaleza mercantil. Su carácter mercantil se deriva de

${ }^{13}$ Arrêt de la Cour de Cassation 5 dic 2001, arrêt de la Cour d'Appel d'Orléans 16 fev. 2012.

${ }^{14}$ MarTí Miravalls, Jaume. «El contrato de gérance-mandat: aproximación a los contratos de gestión empresarial». Revista Aranzadi de Derecho Patrimonial, 2008-2, $\mathrm{n}^{\circ} 21$, p. 5 .

${ }^{15}$ Martí Miravalls, Jaume. «El contrato de gérance-mandat: aproximación a los contratos de gestión empresarial». Revista Aranzadi de Derecho Patrimonial, 2008-2, $\mathrm{n}^{\circ} 21, \mathrm{p} .7$. 
su carácter interempresarial, pues tanto gestor como empresario de alojamiento turístico gestionado son empresarios, por lo que puede entenderse mercantil por analogía conforme a lo dispuesto en el art. 2 del Código de Comercio (en adelante CCo). En consecuencia, deberá aplicarse a dicho contrato las reglas contenidas en los arts. 50 y siguientes del CCo, así como las reglas de la Ley 3/2004, de morosidad, en caso de que una de las partes incurra en mora. Por otra parte, su posible regulación, al ser legislación mercantil, corresponderá al Estado como competencia exclusiva.

No obstante, hasta ahora no se ha regulado en derecho español, por lo que podemos calificar el contrato de gestión hotelera como un contrato atípico, de colaboración empresarial. En consecuencia, se regula por el contenido de su clausulado, siguiendo el principio de autonomía de la voluntad, reconocido por el art. 1255 del Código Civil (en adelante, CC), y en caso de laguna, por las normas generales de las obligaciones y contratos (primero las mercantiles y, supletoriamente, las civiles). No es frecuente encontrar lagunas, pues es un contrato muy largo y detallado. Pero en el caso de existir, la jurisprudencia del Tribunal Supremo (en adelante, TS), señala que para integrar los contratos atípicos el intérprete debe acudir a la regulación de los contratos típicos con los que aquellos guarden más proximidad económica. Seguidamente procederemos a analizar la similitud de los contratos legalmente típicos que más se asemejan al contrato de gestión de negocios de alojamiento turístico socialmente típico, es decir, el que contiene las cláusulas más habituales de los contratos que hemos analizado.

En primer lugar, el contrato de gestión, como contrato de colaboración entre empresarios, puede considerarse similar al contrato de sociedad, que sería sociedad mercantil irregular, al ser su objeto social mercantil, y no constar en el Registro Mercantil. Para que sea considerado contrato de sociedad es necesario que exista affectio societatis, voluntad de constituir una institución jurídica con carácter de permanencia y de naturaleza diferente a la de los contratantes, que se situarían en una misma posición jurídica. Para determinar la existencia de la affectio societatis, son datos relevantes el tipo de remuneración, que debe consistir en una participación en beneficios, las aportaciones de capital, o el acuerdo de reparto de gastos (Expense Sharing Agreements). Desde este punto de vista, algunos contratos de gestión, podrían calificarse como societarios, pero no será lo habitual.

En segundo lugar, es posible calificar el contrato de gestión como contrato de arrendamiento de servicios, lo que nos acercaría al con- 
trato laboral. Es el régimen aparentemente más adecuado a los supuestos de gestión en los que la única aportación del gestor sea su trabajo y no exista una pretensión de incluir el negocio de alojamiento turístico en una cadena hotelera del gestor. El contrato de arrendamiento de servicios implica una obligación de medios, propia de gestiones de asesoramiento legal, contable, etc. Los pocos pronunciamientos jurisprudenciales españoles, han calificado el contrato de gestión como contrato de arrendamiento de servicios cuando el gestor es una persona física y esta característica del gestor es esencial, es decir, se realiza intuitu person ${ }^{16}$. Con todo, parece más adecuado que a estos casos se les aplique, o bien la regulación laboral propia de los contratos de alta dirección, o bien las reglas del gestor de negocios ajenos del CC, o bien, dado el ámbito mercantil en el que se encuadra el contrato de gestión hotelera, las normas del CCo sobre la figura del factor. Esto es especialmente relevante cuando los gestores actúan como tales frente a terceros una vez ha finalizado el contrato de gestión, sin que el principal haya impedido la continuidad de la apariencia de representación. En estos casos, el art. 284 CCo impone la responsabilidad solidaria del principal (empresario de alojamiento turístico gestionado) y el gestor respecto a los contratos celebrados por este último. No tratamos en este artículo los contratos de gestión en los que el gestor solo aporta sus servicios y no pretende la integración del hotel en una cadena hotelera.

Conforme a la definición antes expuesta, en el contrato de gestión el gestor debe actuar en nombre y por cuenta del titular del alojamiento turístico gestionado, lo que cumple con los requisitos que permiten calificarlo como contrato de comisión, regulado conforme a los arts. 244 y siguientes del CCo, y supletoriamente por las normas del contrato de mandato, de los arts. 1709 y siguientes del $\mathrm{CC}^{17}$. Ahora bien, el contrato de comisión está pensado para actos de representación aislados, mientras que el contrato de gestión es de tracto sucesivo. El contrato de representación de tracto sucesivo regulado en el ordenamiento jurídico español es el contrato de agencia. Por ello, entendemos aplicable la norma reguladora del contrato de agencia, la Ley 12/1992, del contrato de agencia (en adelante LCA), al contrato de

${ }^{16}$ Sentencia de la Audiencia Provincial de Cantabria (Sección 4. ${ }^{\text {a }}$, núm. 4/2008 de 3 de enero (JUR 2008\333380). (Caso Hoteles Trébol Cantabria, S. A. v. Palacio de Soñanes, S. L. Ponente María José Arroyo García). Trata de un contrato de arrendamiento de servicios en que la parte actora debía gestionar el personal, realizar la gestión hotelera propiamente dicha, realizar la gestión financiera, gestión de compras y por último la gestión comercial.

${ }^{17}$ Alcover GaRAu, Guillermo. «Aproximación al contrato de gestión hotelera», en Revista de Derecho mercantil. N. ${ }^{\circ}$ 237, 2000, p. 1010. 
gestión. Sin embargo, tal aplicación no debe ser automática. La LCA contiene normas imperativas protectoras del agente, que el legislador considera como parte débil en el contrato. Estas normas no son aplicables al contrato de gestión hotelera, al menos, como normas imperativas, aunque podríamos entenderlas como dispositivas. Y ello porque frente al titular del alojamiento turístico gestionado, la cadena hotelera no tiene una posición débil que deba protegerse. El contrato de gestión contiene una causa propia que no contienen los contratos de agencia, de comisión o de arrendamiento de servicios, que lo configuran como un contrato diferente: el gestor (la cadena hotelera) actúa en interés del principal (empresario de alojamiento turístico gestionado), pero también en interés propio (pues, le interesa promocionar su imagen de grupo e incrementar su oferta disponible a las agencias de viaje nacionales e internacionales). Por ello, el titular del alojamiento turístico gestionado no puede dar órdenes que afecten al modelo de gestión (como por ejemplo, modificar el modelo de turismo familiar, o de turismo de aventura, que caracteriza a la cadena hotelera). El agente solo comercializa, mientras que la cadena hotelera realiza toda la gestión, no es mero colaborador. Es más, está implícito en el contrato de gestión que el gestor (la cadena hotelera) actúa normalmente con varios titulares de alojamientos turísticos sin que sea necesario el consentimiento de uno para contratar con el otro, en contra del art. 7 LCA, pues de lo contrario, no podría utilizarse esta modalidad contractual para la expansión de la cadena hotelera. Además, la cadena hotelera siempre tiene pleno poder de representación.

Finalmente, en el contrato de gestión por parte de las cadenas hoteleras existe unas obligaciones accesorias inseparables, sin las cuales este contrato de gestión deja de tener un interés para la cadena. Así, la cadena proporciona un know how a los trabajadores de la propiedad (aunque no a su titular), acuerda localización y obras de instalación, integra al hotel en su red de hoteles (algunos de ellos en franquicia) y promociona la marca de la que es titular. Las obligaciones accesorias que asume son las propias de un franquiciador, y como tal le son retribuidas por el titular del hotel (factura horas de asesoramiento, entrenamiento, y revisiones (Staff fees), obtiene ingresos derivados de los contratos vinculados (suministros...), y obtiene ingresos derivados de las reservas de los clientes, que se realizan a través de su central de reservas. Este punto es clave, pues determina la posición inferior del hotelero y la necesaria protección por parte del legislador en la misma medida que se protege al franquiciado en el art. 62 de la Ley 7/1996, de 15 de enero, de Ordenación del Comercio Minorista 
(en adelante, LOCM) (obligando a la cadena hotelera a inscribirse en un Registro administrativo de franquiciadores, y a ofrecer por escrito información precontractual sobre las condiciones del contrato de franquicia, con especial referencia a la red de franquicias).

\subsection{Elementos personales}

El contrato lo firma el titular de un negocio de alojamiento turístico con un gestor, que es siempre una cadena hotelera, que actúa como gerente del titular del negocio hotelero. La cadena hotelera que actúa como gerente, es una persona jurídica, pues si fuera persona física, se entendería como contrato de prestación de servicios o de trabajo, como contrato de alta dirección. Como son contratos intuitu persona, en especial respecto a la cadena, el titular del negocio hotelero puede vetar el cambio de gestor o el cambio en la estructura del gestor, por ello suelen incluirse expresamente cláusulas que sí permitan la reestructuración societaria de la cadena, o procesos de fusión, asociación u operaciones análogas con cadenas hoteleras de capacidad similar. Ello permite la concentración del sector ${ }^{18}$.

El titular del negocio de alojamiento, que en los contratos de gestión suele denominarse "hotelero», y que también llamaremos principal, puede ser propietario del inmueble o titular de un derecho de uso sobre el mismo (normalmente arrendatario, pero puede ser usufructuario). En este caso, la cadena exigirá al arrendatario que consiga que el arrendador (o, en su caso, el nudo propietario) asuma compromisos que garanticen la pervivencia del contrato de gestión en caso de cambio de arrendatario (o de usufructuario), además de que garantice la solvencia financiera, tanto propia como del titular del uso (para evitar la ejecución de una hipoteca constituida sobre el establecimiento hotelero o sobre el inmueble), y que las posibles limitaciones de la capacidad de endeudamiento del nuevo comprador o arrendatario no afecten a las inversiones que deberá realizar en el hotel ${ }^{19}$.

En ocasiones, el principal no será un único titular. El contrato de gestión de negocio de alojamiento se exige imperativamente para al-

${ }^{18}$ Lozano Romeral, Diego/ SÁnchez Montero, Antonio/ Enseñat Bilbao, Beatriz. «Naturaleza y estructura de los contratos de gestión en cadenas de hoteles». En SEBASTIÁN, Rafael (Coor.) 2012 Práctica Mercantil para Abogados. Los casos más relevantes en 2011 de los grandes despachos. La Ley 2012, p. 636.

${ }^{19}$ Lozano Romeral, Diego/ SÁnchez Montero, Antonio/ Enseñat Bilbao, Beatriz. «Naturaleza y estructura de los contratos de gestión en cadenas de hoteles». En SEBASTIÁN, Rafael (Coor.) 2012 Práctica Mercantil para Abogados. Los casos más relevantes en 2011 de los grandes despachos. La Ley 2012, p. 635-636. 
gunas estructuras de alojamiento tales como los condominios hotele$\operatorname{ros}^{20}$, y los regímenes de aprovechamiento de alojamiento por tur$\operatorname{nos}^{21}$. En muchos casos, este tipo de explotación no lo asumen cadenas hoteleras, no aportando el gestor derechos de propiedad intelectual alguno ni incorporación a redes de comercialización. Sin embargo, nada impide que los gestores sean cadenas hoteleras que, además, integren los alojamientos dentro de su red hotelera.

\subsection{Elementos reales}

El titular del alojamiento turístico aporta el negocio hotelero, como unidad productiva, o exclusivamente el inmueble en casos de condo hoteles o aprovechamiento por turno. Las normas administrativas que imponen la Unidad de explotación (como el art. 33 LTIB) permiten que esta se acredite mediante prueba de propiedad o mediante otros contratos que supongan explotación por terceros (como el contrato de gestión), pero impide la existencia de dos contratos de gestión para la explotación de plazas distintas en un mismo hotel.

Los elementos reales del contrato aportados por la cadena hotelera son los propios de una franquicia: la marca, el know how, la red de comercialización, y la central de reservas. Los derechos de propiedad industrial como patentes, marcas o los derechos de propiedad intelectual son elementos de primer orden en la industria hotelera. Sea cual sea la manera de integrar un negocio hotelero en una cadena, las marcas registradas de la cadena hotelera, así como las no registradas (aunque notorias o renombradas), la propiedad de los sistemas de reservas y de logística, son una fuente potente de control. El mantenimiento del control total del uso de estos elementos modera la poten-

${ }^{20} \mathrm{El}$ régimen de condo hoteles, no regulados por norma estatal alguna, sí se regula en la Ley 8/2012, de 19 de julio, de Turismo de las Islas Baleares, en adelante LTIB (primera que los ha regulado). Su art. 30.4 exige que estos establecimientos «deberán reunir las siguientes garantías: b) Cada uno de los propietarios de las diferentes unidades de alojamiento se comprometerá a que el inmueble en conjunto, incluyendo las zonas comunes y todas las unidades de alojamiento, sea gestionado por una única empresa explotadora. 5. La entidad explotadora deberá acreditar que está habilitada para la explotación de todo el establecimiento en conjunto o, en su caso, de la totalidad de los elementos o las unidades de alojamiento en los que se encuentre dividido, mediante la aportación del título jurídico en el que se soporte lo dispuesto en el apartado anterior.»

${ }^{21}$ En cuanto al aprovechamiento por turno, el art. 25 c) de la Ley 4/2012, de 6 de julio, de contratos de aprovechamiento por turno de bienes de uso turístico exige en este tipo de contratos, "haber celebrado, de conformidad con lo establecido en el presente capítulo, el contrato con una empresa de servicios que reúna los requisitos que a éstas se exijan, salvo que el propietario, cumpliendo los mismos requisitos, haya decidido asumirlos directamente». 
cial amenaza de los socios minoritarios, directivos de la cadena, arrendadores, principales en contratos de gestión, o franquiciados de aprovechar su relación con la cadena hotelera para copiar su modelo de negocio y quedarse con su clientela. Ello permite la expansión internacional de la cadena hotelera por medio de alianzas basadas tanto en capital como en relaciones contractuales. Otros elementos no visibles son de más difícil control, como la información tácita del know how contenida en las rutinas de trabajo, o el entrenamiento del personal. En estos casos, el comportamiento oportunista de la empresa que contrata con la cadena hotelera es más difícil de evitar. El control dependerá de la «capacidad de absorción» de la empresa a la hora de aprender las nuevas rutinas ${ }^{22}$, y del nivel de protección de la propiedad intelectual, industrial y de la normativa de competencia desleal del país donde la cadena hotelera quiera instalarse. En países donde esta protección resulte legal es importante, para la protección jurídica del know how, la elaboración de protocolos de actuación por escrito (Hotel Rules and Standads, Manuales, Checklists).

\subsection{Elementos formales}

Durante la formación del contrato del contrato de gestión hotelera, la cadena hotelera se fija no solo en cuestiones de gestión y operacionales, sino también en la estructura financiera del titular del hotel (asumiendo, en su caso, parte de la propiedad). Es frecuente un proceso precontractual de intercambio de información confidencial en la que se realice una due diligence al hotelero. Por su parte, la cadena hotelera debe cumplir las obligaciones precontractuales exigidas al franquiciador en la LOCM.

La forma escrita es conveniente, pero no obligatoria, con carácter general $^{23}$. Es frecuente que el contrato se divida en varios contratos vinculados ${ }^{24}$. La parte referente a la licencia de marca, sí requiere for-

${ }^{22}$ Contractor, Farok J./ Kundu, Sumit K. «Modal Choice in a World of Alliances: Analyzing Organizational Forms in the International Hotel Sector». Journal of International Business Studies, Vol. 29, No. 2 (2nd Qtr, 1998), p. 333.

${ }^{23}$ Lo que es cierto en España, pero también en Estados Unidos. BMC-THE BENCHMARK MANAGEMENT COMPANY, Plaintiff-Appellant, versus CEEBRAID-SIGNAL CORPORATION, a Florida corporation, CEEBRAID ACQUISITION CORPORATION. UNITED STATES COURT OF APPEALS FOR THE ELEVENTH CIRCUIT 292 Fed. Appx. 784; 2008 U. S. App. LEXIS 19502. September 8, 2008, Decided. El acuerdo oral entre hotelero y cadena es precontrato.

${ }^{24}$ Four Seasons firma 5 contratos vinculados: Hotel Licensing Agreement (que aplica el derecho de Florida sobre secretos comerciales y la jurisdicción de Estados Unidos), Hotel Management Agreement, Hotel Services Agreement, Hotel Advisory Agree- 
ma escrita. Normalmente la licencia de marca se firma en un contrato separado, muchas veces con un derecho aplicable y jurisdicción distintas de la del país donde esté el hotel, buscando la mejor protección de la propiedad industrial. En estos casos, la vigencia del contrato de licencia debe condicionarse a la del contrato de gestión y viceversa ${ }^{25}$. La conveniencia lo es a efectos de prueba, pues el art. 51 CCo establece que los contratos superiores a 1500 pesetas no pueden probarse solo mediante testigos. También es necesaria la forma escrita para las cláusulas de resolución alternativa de conflictos que suelen incluirse en los contratos, pues sin ella, las decisiones no serían ejecutables internacionalmente ${ }^{26}$.

Igualmente importante es la entrega de la documentación complementaria por parte del gestor, lo que se expresa en los Anexos al contrato. Es especialmente importante la entrega de sus manuales de trabajo para la instrucción del personal para que el hotel esté en condiciones de igualarse con otros administrados por la propia cadena. En este proceso debe participar la titular, para coadyuvar al rápido entrenamiento y preparación de los trabajadores. También se aportan el inventario de bienes y elementos, estados financieros, relación y nómina de empleados, programa anual de inversiones.

Pueden existir además exigencias de otorgamiento de escritura pública e inscripción en el Registro de la Propiedad si la gestión es de aprovechamiento de alojamiento por turnos o condo hote ${ }^{27}$.

ment, y Hotel Pre-opening Services Agreement (donde se incluye una cláusula de arbitraje en Miami (Florida). A veces se incluye también un Loan Agreeement). FOUR SEASONS HOTELS AND RESORTS, B. V., versus CONSORCIO BARR, S. A., Defendant-Appellant. No. 05-16351. UNITED STATES COURT OF APPEALS FOR THE ELEVENTH CIRCUIT. 533 F.3d 1349; 2008 U. S. App. LEXIS 14863; 21 Fla. L. Weekly Fed. C 925. July 14, 2008

${ }^{25}$ Beatriz. "Naturaleza y estructura de los contratos de gestión en cadenas de hoteles». En SEbastián, Rafael (Coor.) 2012 Práctica Mercantil para Abogados. Los casos más relevantes en 2011 de los grandes despachos. La Ley 2012, p. 638.

${ }^{26}$ Marriot suele incluir en sus contratos la siguiente cláusula: «9.6 Governing Law: Arbitration: Consent to Jurisdiction. The parties hereto shall use their best efforts to settle any disputes or differences arising out of or relating to this Agreement.... If they do not reach [a] solution within a period of thirty (30) days, then the dispute or difference shall be finally settled by arbitration in accordance with the rules of the American Arbitration Association".

${ }^{27} \mathrm{Si}$ la cadena gestiona un inmueble explotado en régimen de aprovechamiento por turnos, el art. 25.3 de la Ley 4/2012, de 6 de julio, de contratos de aprovechamiento por turno de bienes de uso turístico exige la comparecencia en el otorgamiento de la escritura pública de constitución la comparecencia de la empresa que haya asumido la administración y prestación de los servicios, salvo manifestación expresa del propietario de que son por él asumidos directamente. Además, la escritura deberá inscribirse en el Registro de la Propiedad. Si la cadena gestiona condo hoteles en Baleares, el art. 30.4 LTIB exige que se haga constar, mediante nota marginal en el 


\subsection{Obligaciones del titular del hotel}

El titular del hotel tiene obligaciones de hacer y de no hacer. Como obligaciones de hacer, debe entregar la posesión del hotel, entregar la documentación necesaria para la representación, entregar el fondo de maniobra y de reparaciones, reembolsar los gastos, y pagar la retribución. A diferencia del contrato de comisión, no son cargas, sino obligaciones, tal y como se configura en el contrato, puesto que la cadena puede exigirlos, dado que la cadena tiene interés en que la gestión se lleve a cabo ${ }^{28}$. Las obligaciones de no hacer son: la de confidencialidad, no inmiscuirse en la gestión diaria que corresponde al gestor, y no impedir el uso de la marca por parte del gestor.

\subsubsection{Entrega del hotel}

La entrega del hotel, entendido como unidad productiva susceptible de funcionamiento inmediato implica la entrega de la posesión del inmueble, junto con maquinaria, mobiliario, útiles y enseres ${ }^{29}$ (que suelen reflejarse en inventarios anexos), con los trabajadores (lo que se refleja en un anexo que indica sobre cada contrato de trabajo, su tipo, antigüedad..., aunque no es imprescindible), con las licencias, permisos y autorizaciones de funcionamiento, el titular del hotel asume la obligación de tramitar y obtener los que en el futuro sean precisos (cuyos costes debe asumir el titular, no la cadena) ${ }^{30}$, con seguro de incendios, terremotos, inundaciones que puedan destruir total o parcialmente el hotel (el titular deberá pagar las primas de dichos seguros).

\subsubsection{Dotar de fondo de maniobra}

El fondo de maniobra consiste en una cantidad fija por habitación (por ejemplo, 1000 \$). Mientras no se usan, la cadena se compromete

Registro de la Propiedad, la afección al uso turístico que recae sobre cada unidad de alojamiento y la cesión del uso de dicha unidad de alojamiento a favor de una empresa explotadora.

${ }^{28}$ Alcover GaraU, Guillermo. «Aproximación al contrato de gestión hotelera», en Revista de Derecho mercantil. N. ${ }^{\circ} 237,2000$, p. 1014.

${ }^{29}$ Alcover GaraU, Guillermo. «Aproximación al contrato de gestión hotelera», en Revista de Derecho mercantil. N. ${ }^{\circ} 237,2000$, p. 1012.

${ }^{30}$ Atención, las normas administrativas (que en materia de ordenación turísticas son principalmente autonómicas), no tienen efectos jurídico privados, salvo que así se prevea en el contrato (por ejemplo, una modificación de la categoría, no afecta al contrato de gestión si no se prevé expresamente). 
a depositar los fondos en entidades para generar un interés, que formará parte del beneficio de explotación ${ }^{31}$. La falta originaria de fondos excusa a la cadena de gestionar, aunque se haya aceptado por la firma del contrato. La falta sobrevenida de los fondos necesarios para continuar la gestión es excusa para la suspensión de la actividad de la cadena (conforme al art. 250 CCo). Sin embargo, la cadena hotelera puede continuar con la gestión, para evitar el perjuicio de su marca, lo que genera un crédito de la cadena contra el propietario (reflejados contablemente en sus cuentas anuales).

\subsubsection{Reembolso de gastos de gestión}

Las cantidades gastadas por la cadena en concepto de gestión, deben reintegrarse por el titular del hotel, con los intereses legales desde que se efectuaron (aplicando el art. $278 \mathrm{CCo}$ ). Se les aplica la Ley $3 / 2004$, de morosidad, y en consecencia, no se requiere intimación y el interés de demora es el legal para empresas recogido en su art. 7. No obstante, solo se reembolsan los gastos derivados de la gestión directa del negocio hotelero. No se reembolsarán por el titular del negocio hotelero los gastos que le hubiera originado el ejercicio de su actividad profesional, es decir, lo gastos de mantenimiento de su estructura. Y ello, de la misma manera que el agente no tiene derecho al reembolso de dichos gastos (aplicando el art. 18 LCA).

Por pacto suelen incluirse como gastos de gestión, los siguientes ${ }^{32}$ : FF\&E (Fixed Furniture and Equipment) y OC (Operating Costs), gastos de promoción, marketing, selección de personal, control de plantilla, contabilidad, informática, asesoría fiscal, laboral y jurídica, reparaciones y mejoras, compras de materias primas. Lo normal es que estén perfectamente fijados en anexos al contrato. Suelen ser listados abiertos que concluyen con «demás gastos de explotación del hotel». Se trata de uno de los principales ingresos de la cadena hotelera.

\subsubsection{Pago de la remuneración}

La remuneración será la pactada y, en su defecto, usos de la plaza donde se cumpliere la comisión (art. $277 \mathrm{CCo}$ ).

${ }^{31}$ Alcover GaraU, Guillermo. "Aproximación al contrato de gestión hotelera», en Revista de Derecho mercantil. N. ${ }^{\circ}$ 237, 2000, p. 1014.

32 Alcover GaraU, Guillermo. "Aproximación al contrato de gestión hotelera», en Revista de Derecho mercantil. N. ${ }^{\circ}$ 237, 2000, p. 1015. 
Suele ser mixta ${ }^{33}$ : Cumulativamente se suele pagar al gestor:

- el 3\% al 5\% de ingresos brutos totales, liquidados y abonados mensualmente ${ }^{34}$. A falta de pacto, por analogía con el contrato de agencia, la comisión se pagará no más tarde del último día del mes siguiente al trimestre natural en el que se hubiere devengado (art. 16 LCA). Los ingresos no incluyen las propinas, las facturas no cobradas y provisionadas, las indemnizaciones por seguro, los ingresos por venta de mobiliario y equipos, los intereses de los fondos, ni las subvenciones no tramitadas por el gestor. La comisión sí se considera gasto de explotación.

- un incentivo de 5 al 10\% de beneficios de explotación (Gross Operating Profit), entendidas como ventas netas menos gastos (deducidas amortizaciones, cánones de arrendamiento, impuestos, costes financieros, seguros y provisión de reparaciones extraordinarias), liquidada y abonada anualmente, auditadas las cuentas presentadas por el gestor, por parte de un auditor nombrado por las partes ${ }^{35}$.

En los contratos anglosajones (aunque no en los españoles) suele incluirse una cláusula denominada Owner's Priority que establece que el gestor no cobrará una parte importante de su remuneración mientras el propietario no haya percibido un importe mínimo de beneficios operativos ${ }^{36}$.

La estructura de la remuneración puede ser relevante en el momento de calificación del contrato. En muchas ocasiones, la remuneración suele ser en parte fija, propia de los contratos de arrendamiento, en parte variable, dependiente de los ingresos, de los ingresos netos $^{37}$, o de los beneficios contables después de impuestos. En estos casos, el titular participa de parte del riesgo y ventura, por lo que se le concede cierta participación en la toma de algunas decisiones. En realidad, en estos casos estaremos ante un contrato mixto de arrenda-

33 Alcover Garau, Guillermo. "Aproximación al contrato de gestión hotelera», en Revista de Derecho mercantil. N. ${ }^{\circ} 237,2000$, p. 1015.

${ }^{34}$ Hyatt cobra el $5 \%$ más un $1 \%$ sobre food and beverages.

${ }^{35}$ Mediante pacto se suelen dar otros porcentajes 2,5\% ingresos brutos + porcentajes superiores al 10\% de incentivo según los niveles progresivos de GOP que se superen según los años de contrato (lo que beneficia al propietario, que puede tener garantizado un nivel de GOP concreto por año).

${ }^{36}$ Lozano Romeral, Diego/ Sánchez Montero, Antonio/ Enseñat Bilbao, Beatriz. «Naturaleza y estructura de los contratos de gestión en cadenas de hoteles». En SEBASTIÁN, Rafael (Coor.) 2012 Práctica Mercantil para Abogados. Los casos más relevantes en 2011 de los grandes despachos. La Ley 2012, p. 637.

${ }^{37}$ Ielacoua, Liliana / Smith, Tim. Hotel Contracts: «To Lease or not to Lease?», en HVS London. August 2012. 
miento de industria, de gestión y de sociedad, por lo que encontraremos cláusulas propias de contrato de arrendamiento junto con las de gestión, o incluso podría calificarse de contrato de sociedad, según la relevancia de la remuneración con cargo a beneficios.

\subsubsection{Otras obligaciones del titular del hotel}

El titular del hotel debe dotar de un fondo de reparaciones extraordinarias (3\% de los ingresos), que no se deduce de los ingresos al calcular el beneficio de explotación base de la retribución. El gestor debe usarlo para renovar las instalaciones y activos.

También debe facilitar documentación y poderes (notariales) que acrediten la representación. Debe ser un poder general referido al hotel, otorgado en documento público si así lo solicita la cadena (conforme al art. $1280.5 \mathrm{CC}$ ).

Como obligaciones de no hacer: no debe gestionar directamente el hotel (pues no debe perturbar en la cesión de la posesión); debe permitir la designación de la Dirección del hotel al gestor; no inmiscuirse en la gestión diaria; debe permitir la sustitución del nombre comercial en soportes materiales y documentales; no debe impedir el uso de la marca de la cadena, y debe dejar de usarla cuando finalice el contrato; no debe ceder el contrato sin consentimiento del gestor, para evitar que su nombre comercial o sus métodos de gestión queden desprotegidos (se equiparan las modificaciones estructurales); y debe guardar confidencialidad.

\subsection{Obligaciones del gestor}

El gestor tiene como obligación principal la de gestionar el hotel con fidelidad y lealtad, representando al propietario, devolviendo el hotel tal y como se le entregó, y rindiendo cuentas de su gestión.

\subsubsection{Gestionar el hotel en nombre y por cuenta del propietario}

Si las partes no establecen nada, la obligación de gestionar el hotel se entiende como obligación de medios (exige diligencia, y es el pro- 
pietario quien debe probar la falta de diligencia $)^{38}$. En consecuencia, el gestor es último responsable, por negligente, de las sanciones derivadas del incumplimiento de leyes y reglamentos (en aplicación del art. $259 \mathrm{CCo}$ ), si bien, ello no absuelve la responsabilidad in eligendo et in vigilando del titular del hotel frente a terceros, que podrá repercutir al gestor.

Obviamente, puede pactarse la garantía del gestor de obtener unos resultados mínimos, en cuyo caso se convertiría la obligación de medios en una obligación de resultado. Sin embargo, lo habitual no es pactar expresamente que la obligación del gestor sea de resultado, sino que se exijan al gestor unos objetivos concretos medidos con referencia al RevPAR, o el EBITDA escalados por años, y que su remuneración se calcule sobre estos datos concretos. Una retribución vinculada a los resultados obtenidos podría resultar relevante para determinar la existencia de una obligación de resultados ${ }^{39}$. pero no es un factor decisivo, pues debe interpretarse cuál fue la verdadera voluntad de las partes derivada del contrato. De todos modos, aun considerando que se tratara de obligación de medios, el incumplimiento de los objetivos fijados en el contrato permite presumir la culpa del gestor, invirtiendo la carga de la prueba, correspondiendo a la cadena hotelera la prueba de que fue diligente.

Diferente a la fijación de objetivos es la entrega de un presupuesto por parte de la cadena. En estos casos no puede entenderse que el gestor quede vinculado a unos cálculos que deben entenderse como meras previsiones. Así, la doctrina considera que la desviación del presupuesto anual, aunque haya sido sometido a la aprobación del propietario, no es causa de incumplimiento ${ }^{40}$. La jurisprudencia menor así lo ha entendido. La sentencia de la Audiencia Provincial de Madrid, núm. 87/2007, de 20 de febrero ${ }^{41}$. considera válida la resolución del contrato por el titular del hotel, debido al incumplimiento de

${ }^{38}$ Alcover Garau, Guillermo. "Aproximación al contrato de gestión hotelera», en Revista de Derecho mercantil. N. ${ }^{\circ} 237,2000$, p. 1022). Aunque no se trata de una cuestión pacífica en la doctrina. Pérez Moriones la considera una obligación de resultado.

${ }^{39}$ Lozano Romeral, Diego/ Sánchez Montero, Antonio/ Enseñat BilbaO, Beatriz. «Naturaleza y estructura de los contratos de gestión en cadenas de hoteles». En SEBASTIÁN, Rafael (Coor.) 2012 Práctica Mercantil para Abogados. Los casos más relevantes en 2011 de los grandes despachos. La Ley 2012, p. 643.

${ }^{40}$ Lozano Romeral, Diego/ Sánchez Montero, Antonio/ Enseñat Bilbao, Beatriz. «Naturaleza y estructura de los contratos de gestión en cadenas de hoteles». En SEBASTIÁN, Rafael (Coor.) 2012 Práctica Mercantil para Abogados. Los casos más relevantes en 2011 de los grandes despachos. La Ley 2012, p. 641.

${ }^{41}$ Sentencia de la Audiencia Provincial de Madrid, núm. 87/2007, de 20 de febrero. (caso Directorio Inmobiliario SA v. Partner Hotels and Inss, S. L.), 
la cadena Partner, por malas prácticas directivas ${ }^{42}$, que la alejaron de cumplir los objetivos del presupuesto anual. Siendo el factor decisivo la falta de diligencia y considerando la desviación de presupuestos un indicio de la misma.

Finalmente, para evitar la polémica sobre el carácter de la obligación del gestor, aunque no sean decisivas por sí mismas, son frecuentes las cláusulas que manifiesten que esta es de medios, tales como la siguiente: "Es obligación del gestor la adopción de cuantas medidas sean necesarias para la mejor organización, más alto rendimiento y mayor prestigio del hotel cuya administración se encomienda» ${ }^{43}$.

El titular hotelero suele limitar la capacidad de gestión de la cadena hotelera ${ }^{44}$. Corresponde al titular hotelero aprobar el presupuesto anual, los gastos que superen un porcentaje determinado de la partida de gastos prevista en el presupuesto aprobado para el ejercicio, la suscripción de contratos de endeudamiento, los contratos cuya duración supere un tiempo mínimo establecido, la contratación de trabajadores que superen determinadas condiciones (sueldo, antigüedad, normalmente en un plazo de quince días), y los precios de las habitaciones, y de las comidas y bebidas.

\subsubsection{Deber de fidelidad y lealtad}

Como gestor del titular del hotel, la cadena hotelera debe actuar de buena fe. La buena fe debe aplicarse para interpretar e integrar los contratos, pues así lo dispone el art. $1258 \mathrm{CC}^{45}$. Ello que se traduce en un deber de fidelidad y lealtad del gestor que se concreta en las siguientes obligaciones:

- Invertir correctamente el Fondo de maniobra y el Fondo de reparaciones. Su inversión inadecuada (por ejemplo destinada

${ }^{42}$ Compras conforme a manual de la cadena hotelera Partner, sin buscar otros proveedores mejores, suministros exagerados, lencería mal gestionada, falta de control de tiempos de limpieza, deficiente sistema de formación y mal sistema informático, venta de habitaciones por debajo del precio de mercado de 4 estrellas, (19 € pensión completa).

${ }^{43}$ Alcover GaraU, Guillermo. "Aproximación al contrato de gestión hotelera», en Revista de Derecho mercantil. N. . 237, 2000, p. 1017.

${ }^{44}$ Lozano Romeral, Diego/ Sánchez Montero, Antonio/ Enseñat Bilbao, Beatriz. «Naturaleza y estructura de los contratos de gestión en cadenas de hoteles». En SEBASTIÁN, Rafael (Coor.) 2012 Práctica Mercantil para Abogados. Los casos más relevantes en 2011 de los grandes despachos. La Ley 2012, p. 641.

${ }^{45}$ ALCOVER GARAU, Guillermo. "Aproximación al contrato de gestión hotelera», en Revista de Derecho mercantil. N. ${ }^{\circ}$ 237, 2000, p. 1017. 
a cubrir falta de efectivo en otro hotel del grupo) da lugar a la obligación de restitución del capital más el interés legal más daños y perjuicios (art. $264 \mathrm{CCo}$ ), sin perjuicio de la posible tipificación penal como apropiación indebida.

- No aceptar otras remuneraciones derivadas de la gestión. Si se obtienen descuentos deben atribuirse al propietario. Las propinas del personal corresponden a este. El gestor sí puede ingresar por gestión no vinculada directamente con el hotel, por ejemplo, por el uso de su central de reservas por parte de los clientes del hotel.

- No integrar en la cadena un hotel que entre en directa competencia con el gestionado

- Prohibición de competencia, que no puede superar los 2 años (art. 20 LCA).

- Que la política de expansión de la cadena no perjudique al hotel gestionado. Por ejemplo, que la cadena no dé preferencia o desvíe clientela del hotel a otros hoteles de la cadena, o que en la gestión de los overbooking no se desvíen los clientes a hoteles de la cadena de peor calidad.

- Deber de secreto durante su gestión y tras finalizar las misma. Suele pactarse contractualmente, durante un plazo usual mínimo de 2 años.

- Imposibilidad de adquirir el hotel por compra, aunque sea en subasta, por sí ni por persona intermedia (art. 1459.2 CC). Para adquirirlo el gestor necesitaría el consentimiento del titular del negocio. Suele articularse este consentimiento en el mismo contrato, al reconocer a favor del gestor un derecho de adquisición preferente a favor del gerente en caso de venta por el titular. El derecho de preferencia se concede al final del periodo a favor del gestor. Si el titular pretende arrendar el negocio u otro contrato de gestión a un competidor, debe comunicarlo al gestor, y el gestor podrá optar en idénticas condiciones, en el plazo pactado (normalmente preaviso de un mes y a ejecutar en dos), y comunicándolo fehacientemente (según lo pactado) al propietario.

- Llevanza de contabilidad independiente de cada uno de los titulares de los que tenga hoteles (art. 9.e LCA).

- Cumplir las órdenes del titular hotelero que no contradigan su modelo de gestión. No debe olvidarse que la gestión diaria la 
cede el titular no solo en su propio interés, sino también en el interés del gestor, que, además es el que conoce realmente su propio modelo de gestión exitoso.

- A falta de órdenes, la cadena debe gestionar el negocio «conforme al uso de comercio, cuidando del negocio como propio» (art. $258 \mathrm{CCo}$ ). En los casos en que el gestor sea una cadena hotelera, la voluntad de las partes es precisamente la de que el gestor cuide el negocio y lo gestione como el resto de hoteles de la cadena.

\subsubsection{Representar al titular del hotel}

\subsubsection{Alcance del poder}

Para poder representar al titular del hotel, este debe entregar al gestor un poder lo suficientemente amplio como para permitirle ejercitar todos los actos de gestión ordinaria del hotel, ya sean jurídicos como de hecho (organización contable, facturación y cobro, organización del trabajo, etc.). Así el gestor debe poder celebrar, en nombre y por cuenta del titular, contratos de hospedaje, de contingente, de suministro, laborales, o de seguros ${ }^{46}$. Esta función ofrece ventajas notables al titular, pues la capacidad de negociación de la cadena con agencias de viaje mayoristas, proveedores, sindicatos (convenios colectivos de empresa) y aseguradores es mucho mayor.

Este poder no incluye los actos de disposición (salvo los de suministro de bebida y comida), gravamen, o endeudamiento. Respecto a los contratos de arrendamiento, normalmente quedan excluidos, pero en ocasiones se incluyen cláusulas que permiten al gestor la celebración de contratos de alquiler de duración no superior a la duración del contrato de gestión.

\footnotetext{
${ }^{46}$ En especial, suele pactarse la obligación de contratar y pagar en nombre y por cuenta del propietario, todos los seguros excepto los que cubran los daños sobre los activos del negocio, conforme a cláusulas como la siguiente: «La Gerente (tomador) suscribirá en nombre y por cuenta del hotel (asegurado) y previa aprobación de la propietario las coberturas del seguro general de responsabilidad civil hacia terceros, excluyendo al personal del hotel, el de responsabilidad de automóviles, de daños contra pérdidas o responsabilidad por lesiones personales, fallecimientos o daños resultantes de la operación del hotel, además del de fidelidad y honestidad y contra cualquier otro riesgo de operación, excluyendo los activos fijos, mientras que la Titular suscribirá el seguro sobre los activos».
} 


\subsubsection{Irrevocabilidad del poder}

El poder debe ser irrevocable, pues no solo el titular del hotel, sino también la cadena hotelera que lo gestiona, tienen un interés en el ejercicio del mismo. La irrevocabilidad del poder conviene pactarla expresamente, pues la regla general es que el poder sea revocable salvo que expresamente se indique otra cosa (art. 279 CCo).

La jurisprudencia del TS reconoce que el pacto de irrevocabilidad del poder es válido si el apoderado tiene interés en el asunto ${ }^{47}$, pues la irrevocabilidad puede darse como contraprestación o como garantía, en cuyo caso no se da en exclusivo interés del apoderado. En este caso, el poder solo será revocable en los términos del contrato que lo creó, por ejemplo, por exclusiva voluntad del apoderado.

La cuestión de si puede entenderse tácitamente irrevocable el poder dado por el titular a la cadena hotelera gestora debe resolverse caso por caso. Es cierto que existe una justificación jurídico-económica a favor de esta posibilidad en los contratos de gestión hotelera. Esta es la de evitar que la relación quede a merced de una de las partes (lo que está prohibido por el art. 1259 CC). Es más, las cadenas hoteleras pueden haber incluido esta cláusula de irrevocabilidad en contratos previos firmados con el mismo titular, o con otros, de manera suficientemente reiterada como para que pueda considerarse un uso interpretativo o normativo.

En EE. UU., la regla es que el poder otorgado a la cadena hotelera es esencialmente revocable, y que para que pueda entenderse irrevocable es necesario que la cadena acredite un interés especial distinto al derivado del contrato de gestión hotelera ${ }^{48}$.

${ }^{47}$ Alcover Garau, Guillermo. «Aproximación al contrato de gestión hotelera», en Revista de Derecho mercantil. N. ${ }^{\circ} 237,2000$, p. 1020.

${ }^{48}$ GOVERNMENT GUARANTEE FUND OF THE REPUBLIC OF FINLAND v. HYATT CORPORATION US COURT OF APPEALS 3rd CIRCUIT. 95 F.3d 291; 1996 U. S. App. LEXIS 24010; 35 V. I. 483. 12 sept 1996. "Virgin Grand Hotel» o «Hyatt Regency» Resort case. Hyatt contrató con el promotor Great Acres un hotel management agreement de 30 años de duración, limitando el derecho del propietario de extinguir unilateralmente el contrato por pobres resultados (poor performance). Great Acres financió la obra con un préstamo de un fondo de inversión finlandés en el que este manifestó su conocimiento del contrato de gestión. Great Acres no pudo pagar al fondo el préstamo que pidió para construir el hotel, y, por su parte, el fondo quebró y fue rescatado por el gobierno finlandés. El fondo, en manos del gobierno finlandés ejecutó la hipoteca constituida sobre el hotel, y el rematante, 35 Acres, dio por terminado el contrato, comunicándolo a Hyatt. Hyatt se resiste a abandonarlo, alegando que el poder es irrevocable porque se hizo no solo en interés del poderdante, sino también para proteger su imagen, su marca, y garantizar un periodo mínimo de retorno de la inversión que había realizado. La Corte considera que el poder es revoca- 


\subsubsection{Vinculación del gestor a los contratos celebrados con los terceros}

Siguiendo la regla general de la representación, si el gestor actúa en nombre propio, sin indicar el comitente, es responsable directo de los contratos firmados por él, y los terceros no tienen acción contra el comitente. Si la cadena hotelera gestora actúa en nombre del comitente, es decir, del titular del hotel, debe indicarlo por escrito, es responsable el comitente, aunque también el gestor mientras no pruebe la comisión, si el comitente la niega (arts. 245 a 247 CCo).

Ahora bien, el gerente debe tener cuidado con la apariencia: el nombre comercial que aparece externamente en soportes materiales del hotel o en documentación puede ser importante respecto a terceros, vinculando al gerente como factor notorio. Y precisamente esta será la situación habitual, pues, dado que la cadena hotelera tiene interés en comercializar el hotel como parte de la cadena, es habitual que en estos contratos se incluya una cláusula en la que el propietario autorice expresamente al gestor para que cambie el nombre comercial del hotel por el nombre elegido por el gestor, tanto en soportes materiales y documentales, así como promocionarlo con la marca y logotipo de la cadena hotelera. Los clientes del hotel, traídos por la cadena gracias a sus redes de comercialización, creen que la cadena es la propietaria, lo que hace a ésta responsable frente a ellos de los incumplimientos del hotel. Por ello, la cadena está legitimada pasivamente en demandas de responsabilidad civil derivadas de la explotación, sin perjuicio de su repetición al principal ${ }^{49}$.

ble porque Hyatt no ha probado que exista un interés específicamente protegido con el poder diferente al que es propio de cualquier contrato de management hotelero. En consecuencia, Hyatt debe entregar la posesión al propietario 35 Acres. (Sin perjuicio de que esta sea ordenada y permita a Hyatt recuperar su inversión).

${ }_{49}$ Sentencia de la Audiencia Provincial de las Islas Baleares (Sección 5. a , núm. 277/2006, de 12 junio (AC 2006\1158). Ponente Mateo Ramón Homar. (Caso Elena v. Hotetur Club SL). Se trata de una demanda de responsabilidad civil por una caída de un cliente del IMSERSO en una bañera que no tenía antideslizante ni agarradera. Hotetur era gestora de Airtours Resort Mallorca S. L. que, a su vez había absorbido a Hotel Don Pedro S. A., que era arrendataria del hotel propiedad de Hotel Fil de Ferro S. A. Entre otros argumentos señala que en los folletos entregados a los clientes aparece Hotetur como titular de los servicios, que el Hotel se publicita en su web también a efectos de reclamaciones, que en la prensa aparece la vinculación de Hotetur con el hotel, que el Director es empleado de Airtour pero contratado por Hotetur, y que en el contrato de gestión aparecen confusas las obligaciones que se reserva la principal, de lo que se deriva la cuando menos la gestión conjunta. 


\subsubsection{Permiso expreso al gestor para la autocontratación}

Para evitar los problemas generados por la autocontratación, es preciso el permiso expreso del titular del hotel al gestor para que esta sea posible. Ello es necesario, puesto que en múltiples ocasiones lo que pretende la cadena (donde está su negocio) es una integración vertical, para lo que necesita que el hotel contrate con las agencias de viajes de su grupo hotelero los contratos de reserva de plazas en régimen de contingente. Es más, suele ser el mismo titulara hotelero quien incluye la cláusula en el contrato que obliga a la cadena a comercializar su hotel a través de su red de agencias.

En los contratos de suministro la cadena también debe poder autocontratar, pues parte del negocio consiste en que la contratación se realice según manuales de la cadena que, en muchas ocasiones, como en el caso de las franquicias, exigen la compra de productos a determinados suministradores designados por la cadena hotelera (por ser los de la calidad exigida y por permitir a esta conseguir un incremento de pedidos que perita una reducción de precios unitarios). Al respecto, y cuando la cadena gestora no repercuta esta reducción de precios en beneficio del titular del hotel, entendemos aplicable la jurisprudencia sobre franquicia, que permite al franquiciado (que en este caso sería equivalente al titular) la contratación con terceros siempre que los productos suministrados por estos tengan las mismas características que los del franquiciador, entendiendo nulas las cláusulas que imponen un determinado suministrador al franquiciado, por suponer un abuso de posición dominante, prohibido por el art. 3 de la Ley de Competencia Desleal.

\subsubsection{Hacer uso de la marca}

El titular tiene derecho a exigir que se use la marca de la cadena hotelera. En el caso de que esta tenga varias marcas, la marca usada debe ser la correspondiente a la calidad pactada con la cadena o, en su defecto, de similar calidad a la que tenía el hotel antes de la conclusión del contrato. Se trata de una cláusula relevante, en especial cuando existe una cesión del contrato por parte del gestor. También es posible la cláusula que permita a la cadena hotelera la eliminación o modificación de la marca. En los casos de modificación, salvo pacto, 
la nueva marca debe ser de la misma calidad, dirigirse al mismo tipo de turismo ${ }^{50}$.

\subsubsection{No ceder el contrato}

El gestor se obliga a no ceder el contrato sin consentimiento del titular, pues el comisionista no puede delegar su encargo sin consentimiento del comitente (art. $261 \mathrm{CCo}$ ). El consentimiento puede prestarse en el contrato de gestión de manera anticipada ${ }^{51}$. En caso de cesión autorizada, el gestor responde frente al principal de la actuación del cesionario elegido por él (art. 262 CCo), aunque cabe pacto exoneración ${ }^{52}$.

\subsubsection{Comunicaciones del gestor y rendición de cuentas}

La cadena hotelera gestora debe rendir cuentas de su gestión. Dicha rendición debe ser tanto puntual como periódica (art. 263 CCo). La obligación de información puntual de la marcha de la explotación hotelera se refleja en el art. 262 CCo, y en el art. 9.b LCA. En virtud de ellos, el gestor debe enviar la información necesaria para casos en los que el titular deba dar su consentimiento (conforme al art. 10.3 LCA, debe hacerlo con una antelación de 15 días). En concreto, debe enviar:

- La comunicación de los precios de las habitaciones, o los precios de comida y bebida. La propuesta de precios se envía nor-

${ }^{50}$ Existen empresas de calificación de las marcas turísticas (hotel rating agencies) que permiten acreditar si la marca es de la misma calidad. 21C LLC v. WYNDHAM MANAGEMENT. UNITED STATES DISTRICT COURT FOR THE WESTERN DISTRICT OF KENTUCKY. 2006 U. S. Dist. LEXIS 45298. June 29, 2006. En el HMA se permitía la eliminación de la marca de algunos inmuebles del hotel. Del resto, se mantenía de acuerdo con la clasificación de una hotel rating agency. El contrato incluía la siguiente cláusula: "[Wyndham Management] at any time and from time to time during the Term may determine to change the brand name under which some or all of the hotels currently operated under the "Wyndham» brand name are to be operated. In connection with such change, [21C LLC] agrees that [Wyndham Management] may change the brand name under which [21C] is operated without the consent of [21C LLC] so long as the new brand name is ranked by Smith Travel Research in the same category as, or a higher category than, that in which the "Wyndham» brand name is so ranked».

${ }^{51}$ Alcover GARAU, Guillermo. "Aproximación al contrato de gestión hotelera», en Revista de Derecho mercantil. N. ${ }^{\circ} 237,2000$, p. 1022.

52 21C LLC v. WYNDHAM MANAGEMENT. UNITED STATES DISTRICT COURT FOR THE WESTERN DISTRICT OF KENTUCKY. 2006 U. S. Dist. LEXIS 45298. June 29, 2006. Posible incumplimiento por no avisar de la venta de la cadena a un fondo que separó inmuebles en otra marca y vendió la marca y cedió el resto de contrato de gestión del mismo propietario a otra cadena que no era de lujo.

(C) UNED. Revista de Derecho UNED, núm. 14, 2014 
malmente en enero (invierno) y mayo (verano del siguiente año natural). Es habitual pactar que si el titular no presta consentimiento en un mes, se prorrogan los precios de la temporada anterior. El gestor no puede reducir los precios para adaptarlos al mercado más de un 35\% sin aprobación del propietario.

- Un presupuesto de explotación. Normalmente en agosto. Si en octubre no lo ha aprobado el titular del hotel, se prorroga el anterior actualizado (sumando IPC). Las decisiones que supongan una desviación negativa de más de un $5 \%$, requieren plan de medidas correctoras y aprobación del titular del hotel.

- Un presupuesto de inversiones.

Con periodicidad, el gestor debe enviar al titular:

- Mensualmente debe enviar la cuenta de explotación, y una previsión de tres meses.

— La lista de ocupación y de personal.

- Mensualmente comunicar las reservas de temporada en curso y de la siguiente.

- Trimestral o mensualmente enviar el balance de comprobación.

- Anualmente debe enviar las cuentas anuales, que deben auditarse por un auditor externo nombrado por el propietario, según pacto. Los honorarios derivados de la contabilidad y de las comunicaciones se consideran gastos de explotación.

El titular tiene derecho de inspección contable, y lo llevará por medio de sus representantes, en horario comercial.

La cadena hotelera tiene obligación de llevanza de contabilidad independiente de cada uno de los titulares de los que tenga hoteles (art. 9.e LCA).

La llevanza de la contabilidad es esencial para el cumplimiento de esta obligación de rendición de cuentas. Es frecuente que, además de la contabilidad legal, se pacte, en los contratos internacionales de gestión hotelera, la llevanza de la contabilidad conforme al Plan específico de contabilidad hotelera internacional: Uniform System of Accounts of Hotels publicada por la American Hotel Association, conforme a la cual se calculará la retribución de la cadena hotelera por su gestión ${ }^{53}$.

${ }^{53}$ Retribución y cumplimiento objetivos: All inclusive y Largas estancias, 90\% es RevPAR = ingreso neto de habs (deducido los gastos de desayuno y comida, impuestos indirectos y descuentos)/ n. ${ }^{\circ}$ hab disponibles, o bien, average daily room rate 


\subsubsection{Conservar y devolver el negocio hotelero}

El gestor debe conservar y devolver el negocio hotelero sin minusvaloración (art. $266 \mathrm{CCo}$ ), con el equipamiento equivalente en cantidad y calidad, y en estado normal de desgaste. Normalmente se incluye un protocolo de guía de devolución. El gestor no está obligado a deshacer los cambios estructurales introducidos en el hotel con autorización del titular, y puede retirar las instalaciones no estructurales hechas a su costa.

\subsubsection{Otras obligaciones del gestor}

- Permitir al titular usar excedentes de tesorería si hay fondos para cubrir los pagos futuros.

- Realizar las reparaciones ordinarias derivadas del uso. El gestor no requiere la autorización expresa del propietario para realizar estas obras. Estas reparaciones ordinarias sí se consideran gasto para el cálculo del beneficio de explotación.

- Recibir reclamaciones de clientes (hechas a su costa 9.d LCA).

- Gestionar el software, que será el de la cadena hotelera (adaptaciones del SAP, Fidelio...).

- Llevar la gestión financiera, fiscal, jurídica y económicocontable.

- Llevar la política de personal, contratación, formación y dirección y asignación de funciones del personal. Se trata de una obligación que se mantiene durante la vigencia del contrato. Implica la entrega de manuales, la contratación de formadores, y el control de las funciones, como la de limpieza, etc.

- Suministrar bienes complementarios: bebidas y comida, productos de limpieza, etc. Los precios deben ser aprobados por el propietario. La reposición debe ser conforme a estándares de su clase.

- Diseñar y construir el mobiliario y el inmueble (buscando la estandarización con otros establecimientos de la misma cadena hotelera).

$(\mathrm{ADR}) * \%$ ocupación media diaria. Hoteles de 3 a 5 estrellas: 50 a $70 \%$ es RevPAR, por lo que es mejor GOPPAR. 
- Encargarse de la promoción (ofertas, programas de fidelización), publicidad, relaciones públicas (participación en ferias y convenciones de turismo, centro de negocios) y marketing del establecimiento hotelero. La comercialización del hotel se realizará en su caso, a través de las agencias de su grupo hotelero y siempre por medio de su central de reservas.

\subsection{Extinción del contrato}

El contrato de gestión hotelera se extingue por las causas generales de los contratos. Comentaremos las peculiaridades de la extinción en el caso de que la duración del contrato llegue a su fin, en los casos de denuncia unilateral, y de incumplimiento.

\subsubsection{Duración}

El contrato se extinguirá cuando llegue a su término. La duración pactada es larga, normalmente de 10 a 30 años $^{54}$. Ello es lógico, pues integrar un hotel en una cadena hotelera de ámbito mundial puede tardar unos cinco años hasta que está en plena producción ${ }^{55}$. Es normal que los contratos sean prorrogables normalmente por plazos de cinco años. En la práctica, el preaviso se pacta de 1 año o 9 meses.

Si no se pacta plazo, debemos entender que el contrato lo es por tiempo indefinido (art. 23 LCA). Si no se ha pactado prórroga alguna, podríamos entender aplicable la tácita reconducción propia del contrato de arrendamiento, aplicada por la jurisprudencia como referencia general en los contratos de tracto sucesivo, conforme a la que, de no haber preaviso, el contrato se entendería prorrogado por un año, salvo que existiera un preaviso de quince días. Sin embargo, esta norma supletoria, en especial el breve plazo de preaviso, es inadecuada a la realidad y necesidades del negocio hotelero, que requiere una planificación de la temporada con tiempo suficiente. Entendemos que, para el contrato de gestión, es más adecuada la normativa del contrato de agencia, que, a falta de pacto, señala que la tácita reconducción lo sería por un tiempo indefinido (art. 24.2 LCA), con unos plazos de

${ }^{54}$ Alcover Garau, Guillermo. «Aproximación al contrato de gestión hotelera», en Revista de Derecho mercantil. N. ${ }^{\circ} 237,2000$, p. 1011.

${ }^{55}$ GOVERNMENT GUARANTEE FUND OF THE REPUBLIC OF FINLAND v. HYATT CORPORATION US COURT OF APPEALS 3rd CIRCUIT. 95 F.3d 291; 1996 U. S. App. LEXIS 24010; 35 V. I. 483. 12 sept 1996. 
preaviso legales no tan breves, de 1 mes a 6 meses (art. 25 LCA). Con todo, estos plazos de preaviso son breves para poder preparar la temporada turística siguiente (donde la contratación de los cupos de habitaciones con las agencias de viaje se realiza como máximo con nueve meses de antelación). Por ello, es conveniente, y común, que el preaviso se pacte expresamente.

En ocasiones, se incluye un derecho de adquisición preferente al final del periodo a favor del gestor. Suele pactarse que la opción deba ejercitarla el gestor comunicándola de manera fehacientemente al titular (normalmente con preaviso de un mes).

\subsubsection{Denuncia unilateral}

La extinción por denuncia unilateral es habitual en tiempos de crisis: los titulares quieren reducir sus costes y las cadenas quieren mantener sus ingresos, y la calidad de su marca a cualquier coste. Desde este punto de vista, si se pacta el carácter irrevocable del poder dado al gestor pone a este en una situación ventajosa para denunciar el contrato de manera oportunista. En todo caso, el gestor puede renunciar con preaviso (art. $1736 \mathrm{CC}$ ). A falta de pacto de irrevocabilidad, el propietario puede denunciar unilateralmente el contrato en cualquier momento (art. $279 \mathrm{CCo}$ ) sin necesidad de preaviso. El preaviso habitual en ambos casos suele pactarse de de 3 meses a 1 año.

También suele incluirse la posibilidad de extinguir el contrato cuando se extingan los contratos de contingente celebrados por el gestor con las agencias de viaje.

La buena fe atempera la regla general y exige del titular un preaviso (usualmente de tres meses): cuando la cadena hotelera haya realizado instalaciones que, en principio, deberá desinstalar; cuando la cadena hotelera haya formado trabajadores, por lo que tendrá que recibir una indemnización adecuada.

En caso de venta del hotel se exige al titular un preaviso, para que el gestor pueda ejercitar un derecho de adquisición preferente (si pactado) o pueda reclamar una indemnización (equivalente a percepciones desde venta hasta final).

No es necesario el preaviso, si la extinción tiene lugar por incumplimiento de una de las partes (art.26 LCA). Sin embargo, es discutible la aplicación del mismo artículo cuando afirma que el concurso dará lugar a la extinción automática del contrato. Esta disposición, que se aplica en los contratos de agencia, y que se entiende válida en los pro- 
cesos concursales (art. 63 de la Ley Concursal, en adelante LC), no la entendemos aplicable, pues entendemos que no puede interpretarse analógicamente una norma excepcional, puesto que debe entenderse como excepción el art. 63 LC frente a la regla general del art. $61.3 \mathrm{LC}$, que entiende por no puestas las cláusulas de resolución o extinción automática por declaración de concurso, y la del art. 62 LC, que deja la finalización del contrato sinalagmático en manos del juez de lo mercantil competente.

\subsubsection{Incumplimiento resolutorio}

La extinción por incumplimiento sigue las reglas generales del art. 1124 CC, que da a la parte que sufre el incumplimiento la facultad de resolución, que implica restitución, más daños y perjuicios. El incumplimiento debe serlo de una obligación principal, o un incumplimiento esencial de una obligación secundaria. En todo caso, en el contrato se suelen detallar las obligaciones consideradas esenciales cuyo incumplimiento pueda dar lugar a la resolución del contrato ${ }^{56}$. En cualquier caso, debe existir un incumplimiento grave, una circunstancia que haga imposible la ejecución, que suponga una desviación significativa de los objetivos de rentabilidad (tras otorgar un periodo de gracia). La desviación se obtiene comparando estos con: los objetivos pactados o los presupuestados y los obtenidos por explotaciones competidoras $^{57}$.

${ }^{56}$ Son cláusulas resolutorias típicas:

- la resolución de incumplimiento por no alcanzar un $80 \%$ del beneficio bruto presupuestado. Si el gestor no completa la diferencia en 60 días desde el informe de auditoría. La resolución se hace efectiva con el fin de la temporada turística. Salvo que el gestor acredite que la caída del beneficio es común en hoteles de semejante categoría o situación.

- la resolución por cambio de titularidad de la propiedad. El propietario saliente debe indemnizar honorarios de gestión esperados menos el 65\% (por gastos de gestión no devengados) más intereses.

- Se suele pactar el derecho de subsanación por parte del incumplidor, salvo que el incumplimiento sea esencial. Quien sufre el incumplimiento debe dar un preaviso (normalmente se pacta un preaviso de 30 días), para la subsanación, transcurrido el cual, puede solicitar la resolución contractual. PLATINUM PORTFOLIO, LTD., a Texas Limited Liability Partnership v. SUPERIOR LODGING, INC., an Arkansas Corporation. 3-03-CV-730-AH. UNITED STATES DISTRICT COURT FOR THE NORTHERN DISTRICT OF TEXAS, DALLAS DIVISION. 2004 U. S. Dist. LEXIS 11853. June 17, 2004, resolución por incumplimiento de rendición de cuentas, después de problemas con el director. Se debe pagar la remuneración del periodo cumplido, incluidos los 30 días.

${ }^{57}$ Lozano Romeral, Diego/ Sánchez Montero, Antonio/ Enseñat Bilbao, Beatriz. «Naturaleza y estructura de los contratos de gestión en cadenas de hoteles». En SE- 
La indemnización suele pactarse expresamente. A falta de pacto, entendemos que parece razonable aplicar las reglas previstas para el contrato de agencia (art.28 LCA, sobre indemnización por clientela, y art. 29 LCA, sobre amortización por inversiones) sin que puedan considerarse imperativas, pues están pensadas para un agente que esté en posición de inferioridad respecto del principal, cosa que no ocurre en la relación entre el titular del hotel y la cadena hotelera. En cualquier caso, el gestor mantiene su ventaja en caso de impago del titular: la retención del hotel hasta pago de los gastos no amortizados y de los daños y perjuicios derivados del retraso en su restitución al mandatario (arts. 1728 y $1730 \mathrm{CC})^{58}$.

\section{CONCLUSIONES Y PROPUESTA DE REFORMA DEL PROYECTO DE CÓDIGO MERCANTIL}

En el presente artículo hemos expuesto una de las principales formas jurídicas utilizadas por las cadenas hoteleras para expandirse: la gestión de negocios hoteleros de otros titulares. En el contrato de gestión hotelera la cadena hotelera gestiona la empresa hotelera en nombre y por cuenta de su titular a cambio de una contraprestación. Se trata de un contrato complejo, cuyo régimen jurídico no está regulado por la ley. Por ello suele ser un contrato con amplios clausulados. En defecto de cláusulas hemos integrado el contrato con los de comi-

BASTIÁN, Rafael (Coor.) 2012 Práctica Mercantil para Abogados. Los casos más relevantes en 2011 de los grandes despachos. La Ley 2012, p. 642.

${ }^{58} \mathrm{La}$ jurisprudencia española, en supuestos de contratos de gestión en los que el gestor no era una cadena hotelera se ha pronunciado aplicando las reglas de indemnización especiales del arrendamiento de servicios (art.1594 del Código Civil). La sentencia de la Audiencia Provincial de Cantabria (Sección 4. ${ }^{a}$, núm. 4/2008 de 3 enero (JUR 2008\333380). Hoteles Trébol Cantabria, S. A. v. Palacio de Soñanes, S. L. Ponente María José Arroyo García. Nos encontramos ante un contrato de arrendamiento de servicio en que la parte actora debía gestionar el personal, realizar la gestión hotelera propiamente dicha, realizar la gestión financiera, gestión de compras y por último la gestión comercial. El incumplimiento de la gestión comercial no se considera resolutorio. La gestión comercial era una más de las gestiones encomendadas a la entidad actora. En el Plan de Marketing del año 2005 no se acuerda exclusivamente incluir el hotel en el mercado gay, sino también en hoteles con encanto, bancotel, etc. Ahora bien, como el contrato de arrendamiento de servicio es un contrato basado en la confianza, el hecho de no haber notificado previamente a la entidad demandada su intención de introducir el hotel en el mercado gay, produjo la pérdida de confianza y el desistimiento unilateral del contrato, art. 1594 CC. El desistimiento unilateral exige la indemnización al arrendatario de todos sus gastos, trabajo, utilidad que pudiera obtener por el contrato, art. 1594 del Código civil. Se calcula la indemnización como el margen comercial del precio pactado por el tiempo que quedaba por cumplir. Considera un margen del $25 \%$, aplicable al precio, que era el 3\% RevPAR. 
sión, de agencia y franquicia, siempre teniendo en cuenta que la cadena hotelera tiene una posición dominante. Es un contrato a largo plazo, prorrogable. En él, el titular de la empresa se obliga a entregarla con los elementos necesarios para su funcionamiento, incluyendo un fondo de maniobra, con los poderes suficientes (revocables salvo pacto) para que la cadena hotelera la gestione y la integre en su red de comercialización, bajo su marca. La representación del titular, el control de calidad, la gestión diaria y la contratación (incluida la autocontratación) recae principalmente en la cadena hotelera, pero para tomar las decisiones relevantes, la cadena debe obtener el consentimiento expreso o tácito del titular. La cadena percibe la remuneración por su gestión (consistente en un porcentaje de los ingresos brutos), puede obtener márgenes sobre los suministros que vende al titular, y percibir ingresos por el uso de la marca y de la central de reservas de la cadena. También percibe intereses por las cantidades que haya adelantado si el fondo de maniobra era insuficiente.

La Segunda Edición de la Propuesta de Código mercantil elaborada por la Sección Segunda de la Comisión General de Codificación regula por primera vez este contrato, si bien, lo hace de manera meramente descriptiva e insuficiente, sin resolver los problemas que se generan en la práctica por lo confuso de su calificación, que son los que en este trabajo pretendemos resolver. Su art. 534-4 define la noción de contrato de gestión de establecimientos de alojamiento turístico $^{59}$, sin diferenciar los dos contratos de diversa naturaleza que suelen calificarse como gestión hotelera:

- aquellos en los que el gestor es meramente un mero mandatario sin interés personal en el negocio, cuya actuación es más propia de un arrendador de servicios (al estilo del Derecho francés) o un agente (con la posición de inferioridad digna de protección jurídica del agente contenida en la LCA, que mantendría su imperatividad).

- los que se identifican en el tráfico mercantil hotelero como contratos de gestión, en los que las técnicas de gestión y los signos distintivos deben ser obligatoriamente aportados por el gestor, pues tiene interés en ello, al integrar el hotel en su cadena y permitirle su expansión. En este caso, debería aclararse su naturaleza de contrato de agencia, pero sin protección

${ }^{59}$ Que es aquél en el que "el empresario gestor se obliga a explotar un establecimiento de alojamiento, en nombre y por cuenta y riesgo de su titular, normalmente utilizando sus propias técnicas de gestión y signos distintivos, a cambio de una remuneración económica». 
al agente (gestor) que es, en realidad, la parte dominante. Asimismo convendría aclarar si a este contrato se le aplica también el régimen del contrato de franquicia en todo o en parte.

La Propuesta tampoco aclara el carácter revocable o irrevocable del mandato del titular, ni si el respeto de la autonomía del gestor le permite autocontratar ${ }^{60}$. Se echa en falta el detalle de la obligación de información y rendición de cuentas, en especial, el del derecho de información puntual a instancias del titular del negocio hotelero ${ }^{61}$. Tampoco especifica las obligaciones de cooperación, algunas tan típicas como la entrega del fondo de maniobra o el fondo de reparaciones extraordinarias, con lo que se podrá plantear si, a falta de pacto, se entienden o no incluidos ${ }^{62}$. No especifica si el pago de la remuneración obedece a una obligación de medios o debe estar vinculada a unos resultados ${ }^{63}$. Y finalmente, tampoco resuelve otros problemas jurídico privados que plantea en la práctica la gestión de negocios de alojamiento, en caso de falta de pacto expreso, como la duración del contrato, o el conflicto que surge en la aplicación de normas mercantiles como la Ley Concursal.

${ }^{60} \mathrm{El}$ art. 534-5, enumera las obligaciones del empresario gestor: Su punto 1 establece que "El empresario gestor se obliga a gestionar el establecimiento objeto del contrato, de acuerdo con las instrucciones del titular y respetando su autonomía».

${ }^{61}$ El punto 2 del art. 534-5 señala: «El empresario gestor está obligado a informar y rendir cuentas al titular del establecimiento gestionado en la forma y tiempo pactados, y, como mínimo, una vez al año».

${ }^{62}$ Art. 534-6 afirma, en su punto 1: «El empresario de alojamiento turístico gestionado asume la obligación de entregar al gestor la posesión del establecimiento, así como otras obligaciones de cooperación con el empresario gestor que resulten necesarias para el buen funcionamiento del establecimiento gestionado».

${ }^{63}$ El art. 534-6.2 recoge la obligación del empresario de alojamiento turístico gestionado de "pagar la remuneración pactada y a reembolsar al empresario gestor los gastos en que hubiera podido incurrir por razón del desempeño de la gestión».

(C) UNED. Revista de Derecho UNED, núm. 14, 2014 
